
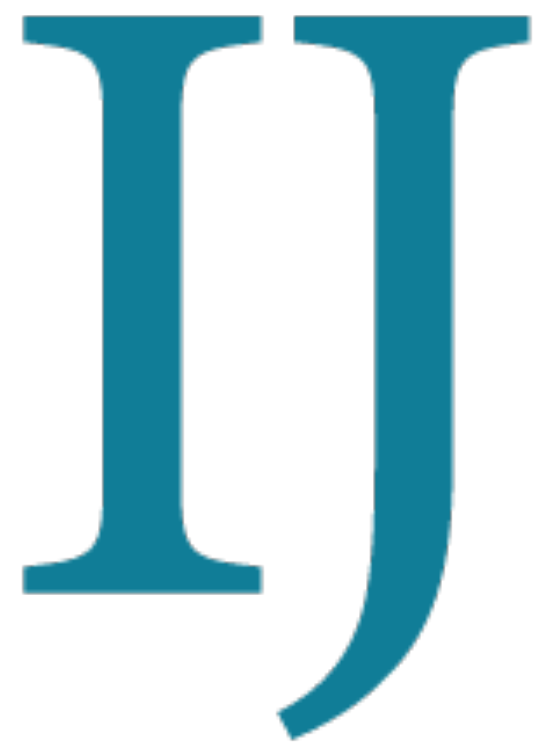



INTERNATIONAL JOURNAL OF CANCER AND BIOMEDICAL RESEARCH

https://jcbr.journals.ekb.eg

Editor-in-chief

Prof. Mohamed Labib Salem, PhD
Altered expression of miRNA-155 and miRNA21 and higher numbers of $T$ cells in the peripheral blood of early diagnosed lung cancer patients

Mohamed L. Salem, Soha Gomaa, Nabila I. El-Desoky, Ashraf F. Brakat, Shymaa S. Morad 


\section{International Journal of Cancer \& Biomedical Research \\ (IJCBR) https://jcbr.journals.ekb.eg}

IJCBR is an Int. journal published by the Egyptian Society of Cancer Research (EACR, established in 2014, http://eacr.tanta.edu.eg) and sponsored by the Egyptian Knowledge Bank (EKB: www.ekb.eg).

IJCBR has been approved by the Supreme Council of Universities, Egypt with score 7 (http://egjournal.scu.eg). The journl is cited by google scholar and registered by Publons (https://publons.com). The journal has recently been evaluated in 2020 by Nature Springer with a good standing.

\section{Scope of IJCBR}

- Drug discovery from natural and synthetic resources

- BioMedical applications of nanotehnology

- Sem cell biology and its application

- Basic and applied biotechnology

- Inflammation and autoimmune diseases

- In slico models and bioinformatics

- In vitro and In vivo preclinical animal models

- Cellular and molecular cancer biology

- Cancer Immunology and Immunotherapy

- New methods for prediction, early detection, diagnosis prognosis and treatment of dieases.

- Immunology in health and dieases

- Anti-microbial defense mechanisms

- Cellular and molecular physhiology and pahthology of diseases

\section{IJCBR Editor,}

Prof. Mohamed Labib Salem, PhD

Professor of Immunology

Faculty of Science, Tanta Universiy, Egypt 


\title{
Altered expression of miRNA-155 and miRNA-21 and higher numbers of $T$ cells in the peripheral blood of early diagnosed lung cancer patients
}

\author{
Mohamed L. Salem ${ }^{1,2}$, Soha Gomaa ${ }^{1}$, Nabila I. El-Desoky ${ }^{1}$, Ashraf F. Brakat ${ }^{3}$, Shymaa S. Morad ${ }^{1}$ \\ ${ }^{1}$ Department of Zoology, Faculty of Science, Tanta University, Egypt \\ ${ }^{2}$ Center of Excellence in Cancer Research, Tanta University Teaching Hospital, Tanta University, Egypt \\ ${ }^{3}$ Radiation oncology Department, Faculty of Medicine, Tanta University, Egypt
}

\section{III}

Background: MicroRNAs (miRNAs) play a significant role in shaping immune response. The expression profile of miRNAs, however, has been found to be affected by the presence of tumor, but whether the incidence of non-small cell lung cancer (NSCLC) alters the expression profile of miRNAs has not been studied. Objective: The current study aims to investigate the expression of miRNAs in the peripheral blood mononuclear cells (PBMCs) from patients with NSCLC as well as to analyze the numbers of helper CD4 ${ }^{+}$ and cytotoxic $\mathrm{CD}^{+} \mathrm{T}$ lymphocytes in PBMCs of the same patients as compared to healthy controls. Methods: PBMCs were prepared from blood harvested from early-diagnosed patients with NSCLC $(n=10)$. The gene expression of miRNAs in PBMCs was measured using microarray and the phenotypic analysis of helper $\mathrm{CD}^{+} \mathrm{T}$-cells and cytotoxic $\mathrm{CD}^{+} \mathrm{T}$-cells in PBMCs was determined by flow cytometry. Results: A significant upregulation of miRNA-21 (2-fold) and downregulation of miRNA-155 (-1.5fold) was observed in the PBMCs of NSCLC patients as compared to healthy controls. The relative and absolute numbers of $\mathrm{CD} 4^{+}$and $\mathrm{CD} 8^{+} \mathrm{T}$-cells were significantly elevated in the PBMCs of NSCLC patients. Conclusion: Our results indicate that both expression levels of miRNA-21 and miRNA-155 in PBMCs and the numbers of $\mathrm{CD}^{+}$and $\mathrm{CD}^{+}$T-cells are altered by the presence of NSCLC.

Keywords: Blood, Leukocytes, miRNA, T-cells, Non-Small Cell Lung Cancer

Editor-in-Chief: Prof. M.L. Salem, PhD - Article DOI: 10.21608/JCBR.2020.21668.1009

\section{ARTICLE INFO}

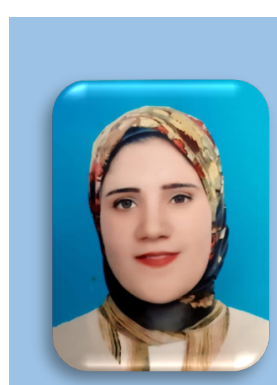

Article history

Received: December 29, 2019 Revised: March 25, 2020 Accepted: March 31, 2020

Correspondence to: Dr. Shymaa S. Morad Department of Zoology, Faculty of Science \&Center of Excellence in Cancer Research, Tanta University Tanta, Egypt Tel: +2-01274272624

E-mail :

shymaasobhy1@gmail.com

\section{INTRODUCTION}

MicroRNAs (miRNAs) are a class of short, evolutionarily conserved, endogenous, small non-coding RNAs that target protein-coding mRNAs at the post-transcriptional level and result in target mRNA degradation or translational inhibition (Macfarlane and Murphy 2010; Solomon and Soria 2016). Circulating miRNA levels in cancer patients are proportional to both the stage of cancer and the response to treatment (Zhang et al., 2007). As such, miRNA play important roles in cancer development and progression.

Non-small cell lung cancer (NSCLC) is characterized by high metastatic potential. Despite that, various therapeutic regimens and new diagnostic methods are developed toward NSCLC; the challenge of drug resistance of this cancer results in poor prognosis. Rapid tumor growth, recurrence, and metastasis are one of the known the principal factors that to contribute to poor therapeutic outcomes in NSCLC patients (Cappuzzo and West 2019). Also, the current understanding of the biologic 
causes of treatment failure in patients with lung cancer is limited and the treatment of refractory or relapsed patients remains a major challenge (Dai et al., 2019). Thus, investigation of the cellular and molecular mechanisms of NSCLC pathogenesis is of paramount significance to advance the development of new and effective therapeutic modalities for NSCLC.

Multiple studies have indicated that miRNAs may provide an innovative approach, at least in part, as biomarkers for cancer treatment (Devaraj and Natarajan 2011). Among these miRNAs, miRNA-21 and miRNA-155 have been found to have an important effect in the occurrence and development of lung cancer. For instance, miRNA-155 has been found to promote the growth and development of tumor cells by regulating a variety of cancer-promoting pathways; with high expression in a variety of malignancies by direct inhibiting the programmed cell death (Gao et al., 2014; Liu et al., 2017). Also, it has considerable regulatory effect in the proliferation, differentiation and growth of T cells (Liu et al., 2015; Xue et al., 2016). Additionally, miRNA-21 is a type of oncogene and has abnormal high expression in many malignant tumors (Ribas et al., 2012) .

The quality and quantity of the immune response inside the tumor microenvironment play significant roles in the tumor progression and aggressiveness (Hong et al., 2016; Pages et al., 2005). T-cells are one of the important factors in the cellular immune response playing a crucial role in the control of cancer (Yi et al., 2015). In particular, CD8 ${ }^{+}$lymphocytes, which represent $80 \%$ of tumor-infiltrating lymphocytes in NSCLC (Das et al., 2013; Kataki et al., 2002), are the effector arm of adaptive immunity producing protection against tumor progression. Infiltrating CD8+ $T$ cells and CD4+ $T$ cells in NSCLC may collaborate to suppress cancer progression and their presence together seems to be an independent suitable prognostic factor in this disease. Despite the previously reported strong association between cancer-related immune response and the clinical outcomes of cancer patients, the role of immunological markers as predictors of NSCLC prognosis is less defined. In the current study, we have examined the relationship between the frequencies of $\mathrm{CD} 8^{+}$ and $\mathrm{CD}^{+}{ }^{+} \mathrm{T}$-cells and the expression levels of miR-
21 and miR-155 in peripheral blood mononuclear cells isolated from NSCLC patients.

\section{MATERIALS AND METHODS}

\section{Patients and blood sampling}

NSCLC peripheral blood (PB) samples $(5 \mathrm{ml})$ were collected from 10 healthy volunteer subjects and 10 NSCLC males ( $n=7)$ and females $(n=3)$ patients with age ranged between 4757 years. The patients were recruited from Chest Department, Tanta University Hospital, Tanta, Egypt between May 2017 and September 2018. The patients were recently diagnosed with nonsmall cell lung cancer; they did not receive prior chemotherapy or radiation therapy included. The patients who received any kind of chemotherapy, surgery or radiation therapy previous to sample collection were excluded from the study. Additionally, patients with concomitant asthma, COPD, bronchiectasis, upper/lower respiratory tract infection in the preceding 4 weeks, active pulmonary tuberculosis, and associated cancer besides lung cancer were excluded from the study. The experimental protocols were approved by the Ethics Committee of Tanta University Hospital, Egypt. All patients delivered written informed approval prior to their enrollment in the present study. More detailed information of patients and controls are shown in Table 1.

\section{Affymetrix Microarray Analysis}

Briefly, total RNAs were extracted with TRIZOL (Invitrogen) in combination with the RNeasy Mini Kit from Qiagen, quantified with Nanodrop Spectrophotometer. Affymetrix microarray analyses were done at Microarray Core Facility at Center of Excellence in Cancer Research, Tanta University, Egypt. For complete miRNA profiling, blood samples were prepared using Flash Tag Biotin HSR RNA Labeling Kit as recommended by the manufacturer's protocol. The samples were hybridized on Gene Chip miRNA 3.0 Arrays (Affymetrix) for $16 \mathrm{~h}$ at $48^{\circ} \mathrm{C}$. The arrays were washed to remove nonspecifically bound nucleic acids and stained on Fluidics Station 450 (Affymetrix) and then scanned on Gene-Chip Scanner 3000 7G system (Affymetrix). Cell files were imported into Chromosome Analysis Suite 1.2 (Affymetrix, Inc) to generate copy number from the raw intensity. Gene Chip miRNA 3.0 cell files were analyzed with Affymetrix Expression Console 
(Version 1.3.1) and Transcriptome analysis console (TAC - version 3.0).

\section{Flow Cytometric Analysis}

Briefly, $100 \mu \mathrm{L}$ fresh peripheral blood samples were stained with monoclonal antibodies (mAbs; obtained from BD Biosciences, CA, USA) against $\mathrm{CD} 4$ and $\mathrm{CD} 8$ receptors using the manufacturer's protocol. Flow cytometry analysis was done using the BD FACSCanto II Flow Cytometer at the Flow Cytometry Core Facility at Center of Excellence in Cancer Research, Tanta University Teaching Hospital, Tanta University, Egypt. Data were analyzed using the software program FlowJo.

\section{Statistical Analysis}

Statistical analysis was performed using the Student's $t$-test. Log-rank nonparametric analysis using Graph Pad Prism (Graph Pad Software, Inc.). All $P$ values were two-sided, with $\mathrm{P}<0.05$ considered significant. Cumulative survival was calculated using a Kaplan-Meier curve. Cell files were analyzed with the Genotyping console for quality control analysis. Samples with QC call above $80 \%$ were admitted into the analysis.

\section{RESULTS}

Expression analysis of miRNA-155 and miRNA21 in peripheral blood of NSCLC patients

The expression of miRNA-155 was significantly down-regulated in NSCLC patients before the induction of chemotherapy as compared to healthy control volunteers "CTRL" (0.04 \pm 0.01 versus $1.14 \pm 0.05, \mathrm{p}<0.01^{* *}$ ) as shown in Figure 1A. However, the expression level of miRNA-21 was up-regulated when compared with healthy control volunteers $(0.12 \pm 0.016$ vs. $0.005 \pm 0.012, p<0.01^{* *}$ ) as shown in Figure 1B.

Analysis of leukocyte populations in the peripheral blood of NSCLC patients

In the present study, we firstly investigated the flow cytometry analysis of different subpopulations of leukocytes, including lymphocytes, monocytes and granulocytes in the peripheral blood mononuclear cells (PBMCs) of NSCLC patients and compared it to healthy control volunteers. We gated on each population and counted the events. As shown in Figure 2, there was a remarkable decrease in the percentage of lymphocytes, monocytes, and granulocytes in PBMCs of NSCLC patients as compared to those of control.
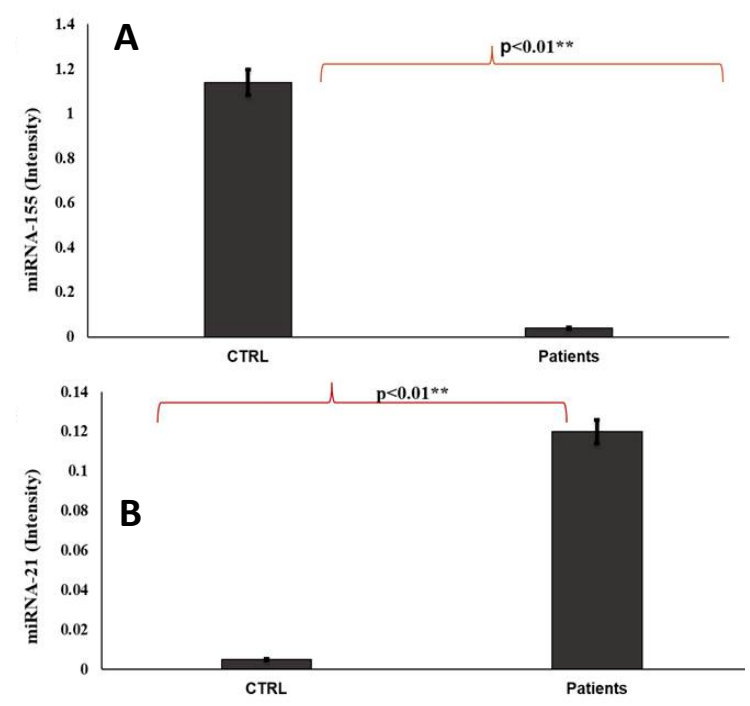

Figure 1. (A) Expression of miRNA-155 and (B) miRNA-21 in NSCLC patients before treatment as compared to healthy control volunteer using microarray.

In PBMCs of NSCLC patients, the absolute number and relative percentage of leukocytes were $(5,350,55.7 \%)$, for lymphocyte were $(1500,15.2 \%)$, for monocytes were $(10,2 \%)$ and for granulocytes were $(2100,39.3 \%)$. These values were lower when compared to those of healthy controls; leukocytes (6880, 91.2\%), lymphocytes (2060, 30.2\%), monocytes (20, $3.5 \%)$ and granulocytes $(4120,60.5 \%)$ as shown in Figure $3 \mathrm{~A}$ and $\mathrm{B}$.

\section{Immunophenotypic analysis of $\mathrm{CD}^{+}$and $\mathrm{CD}^{+}{ }^{+}$ cells in PBMCs}

The phenotypic analysis strategy of T-cells was presented in Figure 4A. From the forward and side scatters, we first gated on the lymphocyte population (P1) and then analyzed the $\mathrm{CD} 4^{+}$and $\mathrm{CD}^{+} \mathrm{T}$ cell subpopulations from $\mathrm{P} 1$. The results showed that the relative numbers of $\mathrm{CD}^{+}$and $\mathrm{CD} 8^{+} \mathrm{T}$ cells were highly increased in PBMCs of NSCLC patients when compared to healthy control volunteers (Fig. 4B). The statistical analyses of the relative and absolute numbers of these 2 subpopulations in NSCLC patients versus control are summarized in Figure $5 \mathrm{~A}$ and $B$ which showed significant increases as compared to those of control volunteers. 

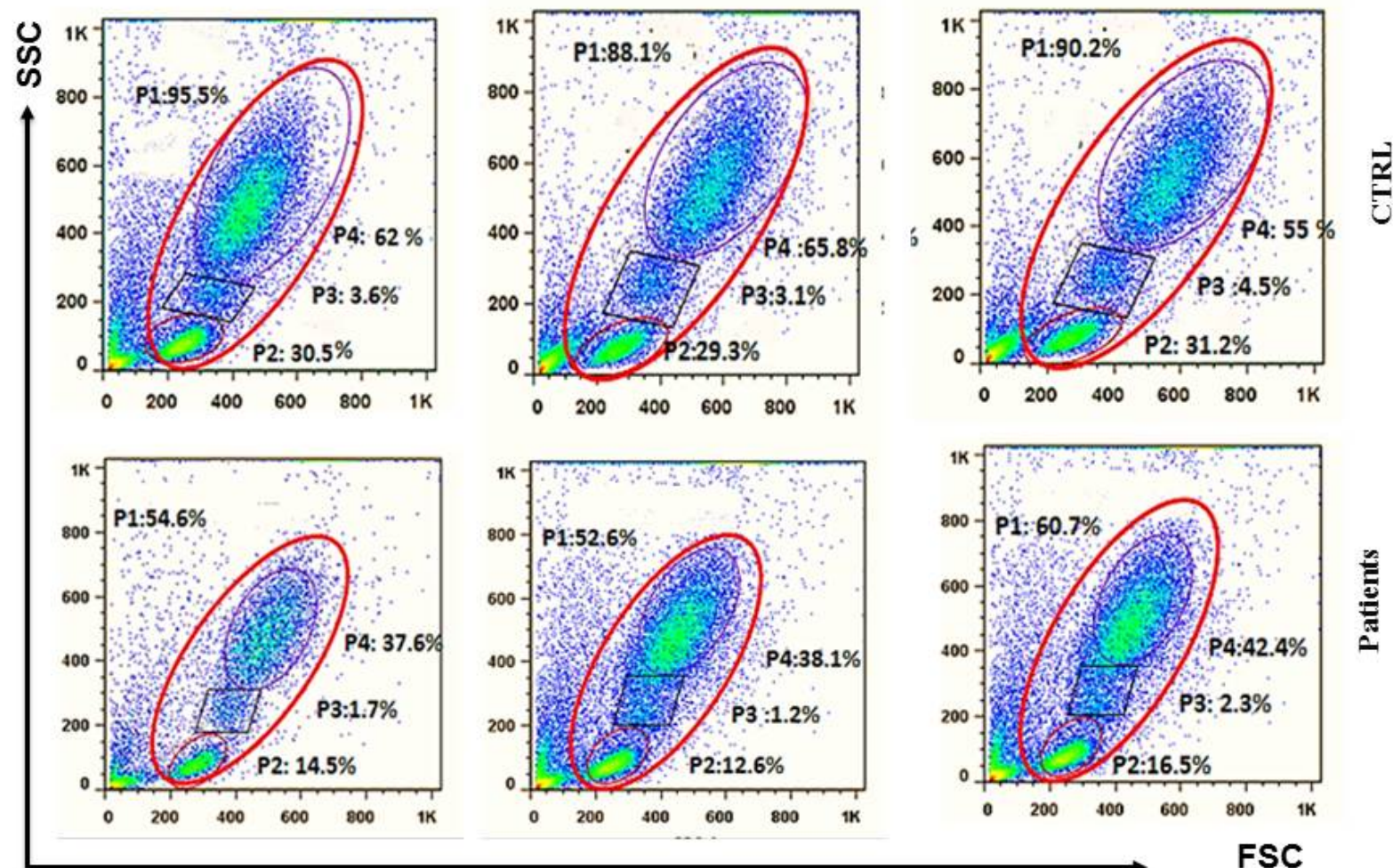

Figure 2. Representative data from flow cytometry analysis of the expression of peripheral leukocytes (P1), Lymphocytes (P2), Monocytes (P3), and Granulocytes (P4) in NSCLC patients against those of control.

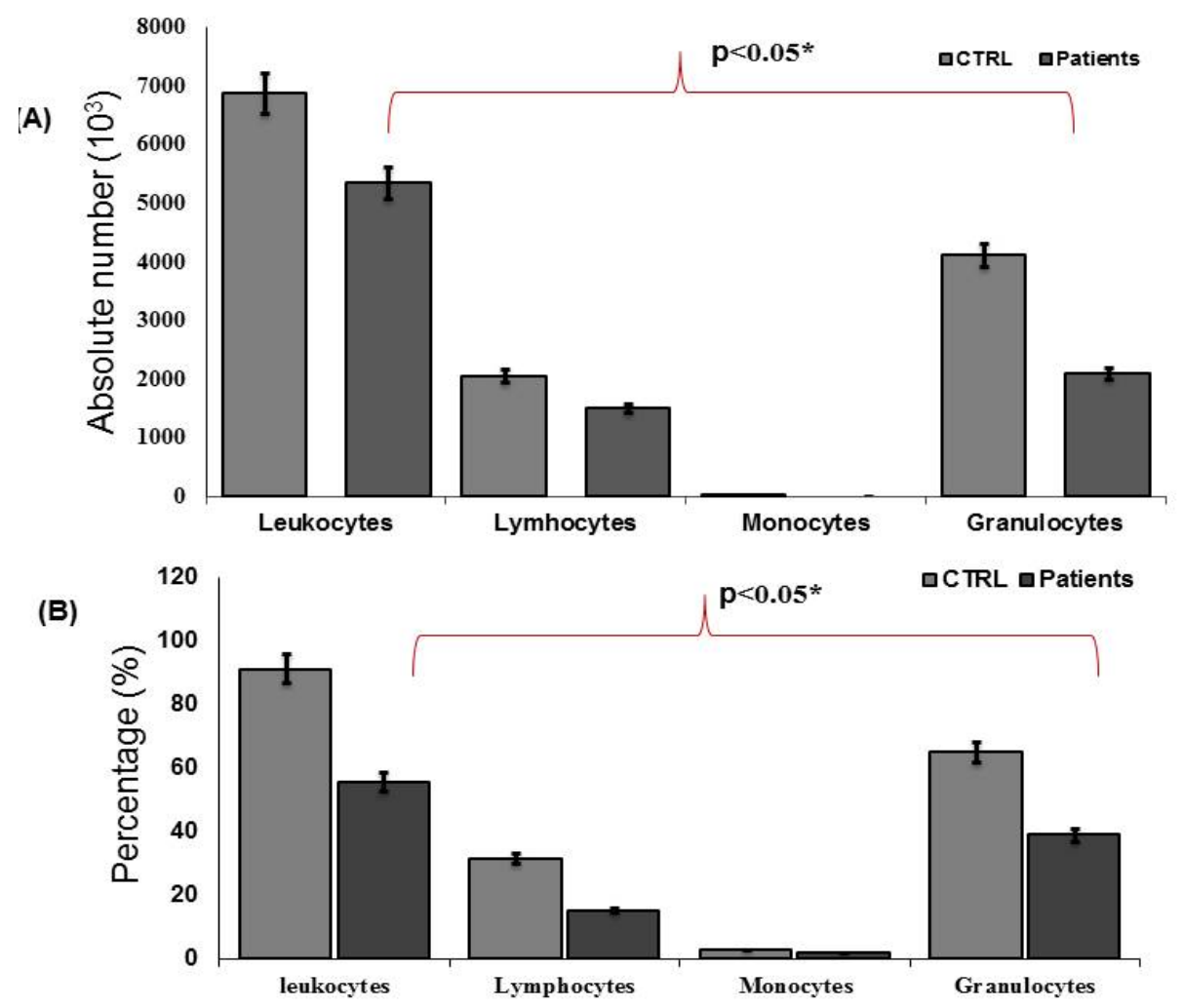

Figure 3. (A) Absolute number and relative percentage of peripheral leukocytes and their different subpopulations in NSCLC patients compared to healthy control volunteers, (B) relative percentage of peripheral leukocytes and their different subpopulations in NSCLC patients against control. 
(A)
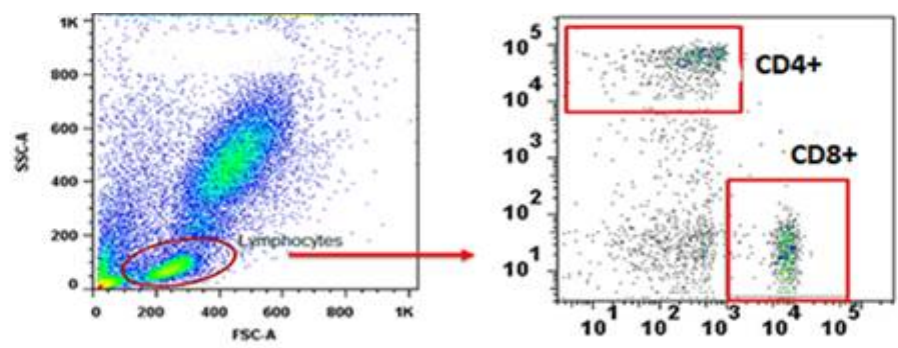

(B)
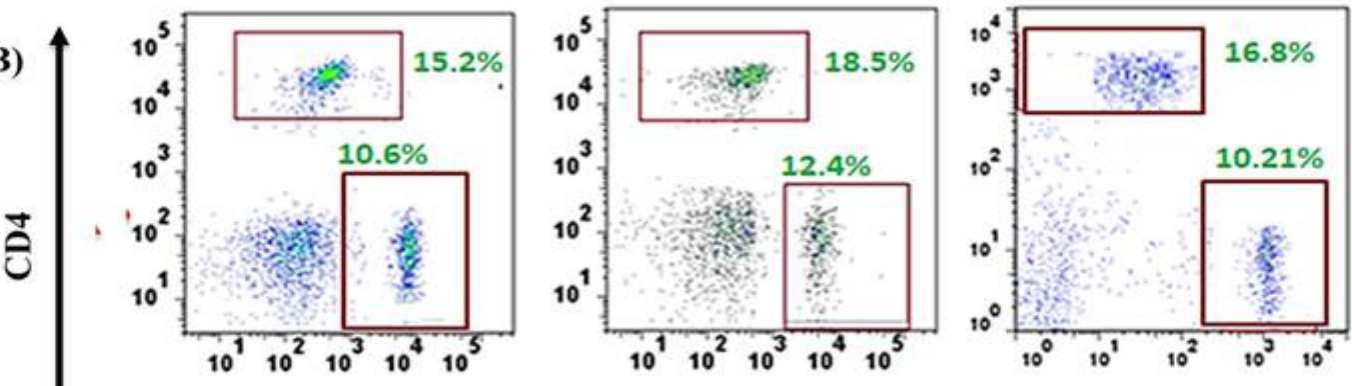

CTRL
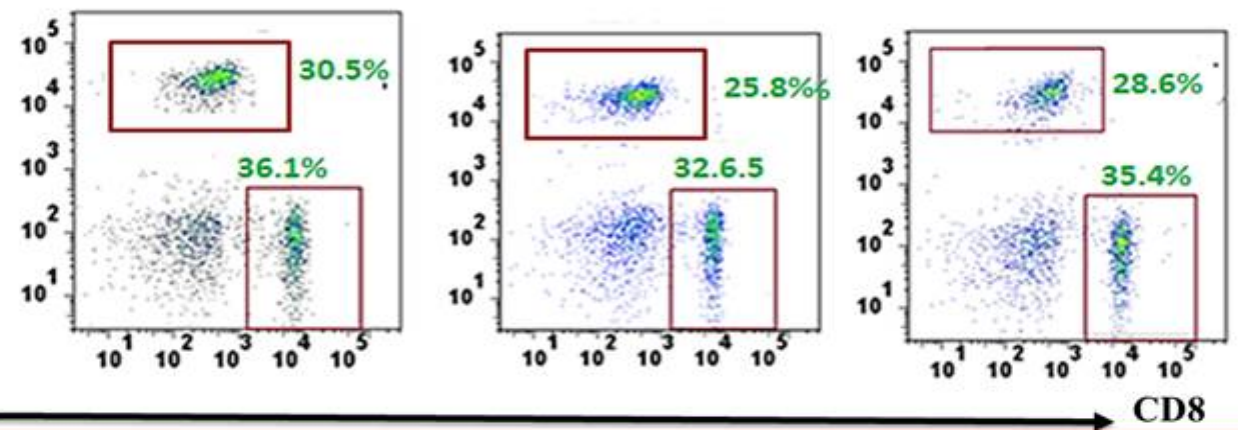

Patients

Figure 4. A representative flow cytometric analysis of $\mathrm{CD} 4^{+}$and $\mathrm{CD} 8^{+}$T-cells in NSCLC patients. (A) Gating strategy of $\mathrm{CD} 4^{+}$ and $\mathrm{CD} 8^{+} \mathrm{T}$-Cells, (B) percentage of $\mathrm{CD} 4^{+}$and $\mathrm{CD} 8^{+} \mathrm{T}$-Cells in NSCLC patients and healthy control volunteers.
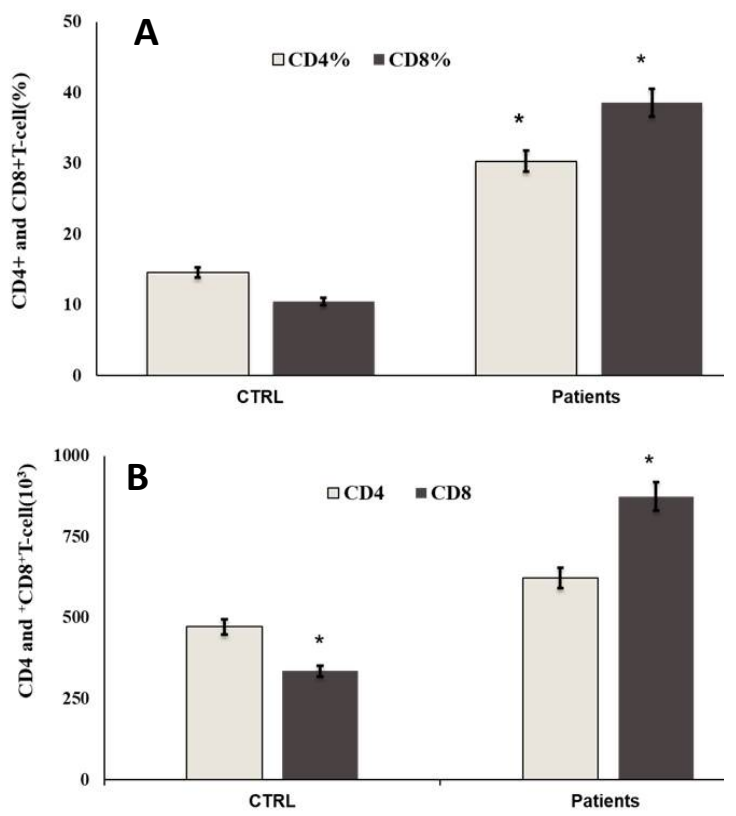

Figure 5. (A) The relative percentage of $\mathrm{CD} 4^{+}$and $\mathrm{CD} 8^{+} \mathrm{T}-$ cells, (B) and their absolute number in PBMCs of NSCLC patients compared to healthy control volunteers and before treatment.

\section{DISCUSSION}

miRNAs have the ability to target various genes including various important signaling pathways that play critical roles in cancer development and progression (Blenkiron and Miska 2007). Several studies have documented that miRNAs are frequently aberrantly expressed in NSCLC (Yang et al., 2018), where their differential expression may be closely related to NSCLC genesis and development (Iqbal et al., 2018). Thus, miRNA expression levels in NSCLC may provide a crucial role in the pathogenesis of NSCLC. As such, studying the alteration in miRNA expression profile in this aggressive malignant tumor seems to be an attractive and effective therapeutic approach for patients.

The present study demonstrates that significant low expression of miRNA-155 and marked high expression of miRNA-21 in NSCLC patients. This data is in line with those of Li et al., (2017) who reported high expression of miRNA-21 in NSCLC 
patients. Similar to our finding, Fortunato et al., (2016) also reported downregulation of miRNA155 considering it as predictor of poor prognosis in NSCLC patients. Taken together, the alteration in the expression of both miR-21 and miR-155 indicate to their important effect in the development of lung cancer.

Importantly, the current study also demonstrates that the numbers of both $\mathrm{CD}^{+}$and $\mathrm{CD}^{+} \mathrm{T}$ cells is significantly elevated in NSCLC patients in comparison to controls. Importantly, the ratio of $\mathrm{CD}^{+} / \mathrm{CD}^{+} \mathrm{T}$ cells was altered as compared to healthy controls. This data is consistent with the findings of Hiraoka et al., (2006) who revealed synergistic high infiltration of both CD4+ and CD8+ T cell in cancer, which usually indicate to a stronger immune reaction against cancer and demonstrate a significantly good prognosis. These data indicate that $\mathrm{CD} 8^{+} \mathrm{T}$ cells could represent key effector cells for anti-tumor immunity affecting immune response against lung cancer and might have prognostic significance.

In summary, both expression levels of miRNA-155 and miRNA-21 and numbers of $C D 4^{+}$ -cells and $\mathrm{CD} 8^{+} \mathrm{T}$-cells are altered in NSCLC patients. These miRNAs may be used as predictors of NSCLC progression. However, further studies are needed with more number of patients to confirm these findings.

\section{REFERENCES}

Blenkiron C, Miska EA (2007) miRNAs in cancer: approaches, aetiology, diagnostics and therapy. Hum Mol Genet 16 Spec No 1:R106113

Cappuzzo F, West H (2019) Chemoimmunotherapy for stage IV non-small-cell lung cancer Authors' reply. Lancet Oncol 20(9):e467

Dai F, Wang J, An H, Lei T, Tang K, Ma X, Duo P, Ren $P$, Chai W (2019) Therapy of (125)I particles implantation inhibited the local growth of advanced non-small cell lung cancer: a retrospective clinical study. Am J Transl Res 11(6):3737-3749

Das LM, Torres-Castillo MD, Gill T, Levine AD (2013) TGF-beta conditions intestinal $T$ cells to express increased levels of miR-155, associated with down-regulation of IL-2 and itk mRNA. Mucosal Immunol 6(1):167-176
Devaraj S, Natarajan J (2011) miRNA-mRNA network detects hub mRNAs and cancer specific miRNAs in lung cancer. In Silico Biol 11(56):281-295

Gao Y, Fu S, Jiang W, Li B, Tian Y, Fu X (2014) [Association of MiR-155 expression with prognosis in resected stage III non-small cell lung cancer]. Zhongguo Fei $\mathrm{Ai} \mathrm{Za} Z \mathrm{Zhi}$ 17(5):417-423

Hiraoka K, Miyamoto M, Cho Y, Suzuoki M, Oshikiri T, Nakakubo Y, Itoh T, Ohbuchi T, Kondo S, Katoh H (2006) Concurrent infiltration by CD8+ $T$ cells and CD4+ T cells is a favourable prognostic factor in non-small-cell lung carcinoma. Br J Cancer 94(2):275-280

Hong C, Mei T, Wang J (2016) [Intercalated Combination of Chemotherapy and EGFR-TKIs versus Chemotherapy Alone in the First-line Treatment of Advanced Non-small Cell Lung Cancer: A Meta-analysis]. Zhongguo Fei Ai Za Zhi 19(12):837-846

Iqbal MA, Arora S, Prakasam G, Calin GA, Syed MA (2018) MicroRNA in lung cancer: role, mechanisms, pathways and therapeutic relevance. Mol Aspects Med

Kataki A, Scheid P, Piet M, Marie B, Martinet N, Martinet Y, Vignaud JM (2002) Tumor infiltrating lymphocytes and macrophages have a potential dual role in lung cancer by supporting both host-defense and tumor progression. J Lab Clin Med 140(5):320-328

Liu F, Song D, Wu Y, Liu X, Zhu J, Tang Y (2017) MiR155 inhibits proliferation and invasion by directly targeting PDCD4 in non-small cell lung cancer. Thorac Cancer 8(6):613-619

Liu J, Shi K, Chen M, Xu L, Hong J, Hu B, Yang X, Sun R (2015) Elevated miR-155 expression induces immunosuppression via CD39(+) regulatory Tcells in sepsis patient. Int J Infect Dis 40:135141

Macfarlane LA, Murphy PR (2010) MicroRNA: Biogenesis, Function and Role in Cancer. Current genomics 11(7):537-561

Pages F, Berger A, Camus M, Sanchez-Cabo F, Costes A, Molidor R, Mlecnik B, Kirilovsky A, Nilsson M, Damotte $D$, Meatchi $T$, Bruneval $P$, Cugnenc PH, Trajanoski Z, Fridman WH, Galon J (2005) Effector memory $T$ cells, early metastasis, and survival in colorectal cancer. N Engl J Med 353(25):2654-2666

Ribas J, Ni X, Castanares M, Liu MM, Esopi D, Yegnasubramanian $S$, Rodriguez $R$, Mendell JT, Lupold SE (2012) A novel source for miR21 expression through the alternative polyadenylation of VMP1 gene transcripts. Nucleic Acids Res 40(14):6821-6833 
Solomon B, Soria JC (2016) The continuum of care for ALK-positive NSCLC: from diagnosis to new treatment options - an overview. Ann Oncol 27 Suppl 3:iii1-iii3

Xue $X$, Liu Y, Wang Y, Meng M, Wang K, Zang X, Zhao S, Sun X, Cui L, Pan L, Liu S (2016) MiR-21 and MiR-155 promote non-small cell lung cancer progression by downregulating SOCS1, SOCS6, and PTEN. Oncotarget 7(51):8450884519

Yang JZ, Bian L, Hou JG, Wang HY (2018) MiR-550a$3 p$ promotes non-small cell lung cancer cell proliferation and metastasis through downregulating TIMP2. Eur Rev Med Pharmacol Sci 22(13):4156-4165
Yi L, Zhao J, Lu J, Chen Y, Huang D, Li YF, Chen L, Yang ZR, Kung HF, He ML (2015) Differential gene expression profile of $\mathrm{CD} 4+/ \mathrm{CD} 8+\mathrm{T}$ cells in patients with hepatitis $C$ virus and/or human immunodeficiency virus infection. Hong Kong medical journal = Xianggang yi xue za zhi 21 Suppl 7:S11-13

Zhang B, Pan X, Cobb GP, Anderson TA (2007) microRNAs as oncogenes and tumor suppressors. Developmental biology 302(1):1-12 


\section{Egyptian Association for Cancer Research (EACR)}

http://eacr.tanta.edu.eg/

EACR is an NGO society that was declared by the Ministry of Social Solidarity (Egypt) No. 1938 in 19/11/2014 based on the initiative of Prof. Mohamed Labib Salem, the current Chairman of EACR. EACR aims primarily to assist researchers, in particular young researchers in the field of cancer research through workshops, seminars and conferences. Its first international annual conference entitled "Anti-Cancer Drug Discovery" was successfully organized in April 2019 (http://acdd.tanta.edu.eg). Additionally, EACR aims to raise the awareness of the society about the importance of scientific research in the field of cancer research in prediction, early diagnosis and treatment of cancer. EACR is also keen to outreach the scientific community with periodicals and news on cancer research including peer-reviewed scientific journals for the publication of cutting-edge research. The official scientific journal of EACR is "International Journal of Cancer and biomedical Research (IJCBR: https://jcbr.journals.ekb.eg) was successfully issued in 2017 and has been sponsored by the Egyptian Knowledge Bank (EKB: www.ekb.eg).

\section{EACR Chairman,}

Prof. Mohamed Labib Salem, PhD

Professor of Immunology

Faculty of Science, Tanta Universiy, Egypt 


\section{Editor-in-Chief}

Mohamed Labib Salem, PhD

Tanta University, Egypt

\section{Managing Editor}

Nehal Elmashad, MD

Tanta University, Egypt

Nabil Mohy Eldin, PhD

Kafrelsheikh University, Egypt

Doaa Al-Ghareeb, PhD

Alexandria University, Egypt

Abdel-Aziz Zidan, PhD

Damanhour University, Egypt

Wesam Meshrif, PhD

Tanta University, Egypt

Rasha Eraky, MD

Tanta University, Egypt

\section{Associate Editor}

Hesham Tawfik

Tanta University, Egypt

Mostafa El-Sheekh

Tanta University, Egypt

Yousry Albolkiny, PhD

Tanta University, Egypt

Gamal Badr

Assuit University, Egypt

Elsayed Salim

Tanta University, Egypt

Essam Elshiekh

Tanta Cancer Center, Egypt

\section{Editorial Board}

\author{
Alberto Montero \\ Taussig Cancer Center, \\ Cleveland, USA \\ Marcela Diaz \\ Cleveland Clinic Foundation, USA \\ Yi Zhang \\ Zhengzhou University, China \\ Shengdian Wang \\ Chinese Academy of Sciences, \\ China \\ Faris Alenzi \\ Prince Sattam bin Abdulaziz \\ University, KSA \\ Mark Robunstein \\ Medical University of South \\ Carolina, USA \\ Mamdooh Ghoneum, DSc \\ Charles Drew University of \\ Medicine \& Science, USA
}

Natarajan Muthusamy, DVM

The Ohio State University, USA

Hideki Kasuya MD, PhD,

FACS

Nagoya University, Japan

Sherif El-Khamisy, MD

Sheffield University, UK

Mohamed Abou-El-Enein,

MD

Charité Universitätsmedizin

Berlin, Germany

Alaa Eldin Almostafa, MD

McGill University, Canada

Amr Amin

United Arab Emirates

University, UAE

AbdeIRahman Zekri

National Cancer Institute, Egypt

Mohamed Attia, MD

Tanta University, Egypt

Mohamed Elshanshory, MD

Tanta University, Egypt

Hussein Khamis

Alexandria University, Egypt

Magdy Mahfouz

Kafr Elsheikh University, Egypt

Ehab Elbedewey

Tanta University, Egypt

Abeer Badr

Cairo University, Egypt

Nadia Hamdy, PharmD

Ain Shams University, Egypt

Ibrahim El-Sayed

Menoufia University, Egypt

Tarek Aboul-Fadl, PharmD

Assiut University, Egypt

Mohamed Noureldin

Banaha University, Egypt

Haiam Abou Elela

National Institute of

Oceanography and Fisherie,

Egypt

Sameh Ali, MD

Nationa Liver Institute, Egypt

Maha EL-Demellawi

City for Scientific Research \&

Technology Applications, Egypt

Desouky A Abd-El-Haleem

City for Scientific Research \&

Technology Applications, Egypt
Ashraf Tabll

National Research Center, Egypt

Wael Lotfy, MD

Alexandria University, Egypt

Olfat Gadallah, MD

Tanta University, Egypt

Nahla Shoukry

Suez University, Egypt

Medhat Eldenary

Tanta University, Egypt

Nagla Sarhan, MD

Tanta University, Egypt

Naglaa Fathy, MD

Zagazik University, Egypt

Azza Hasan Mohamed Menufia University, Egypt

Nanees Gamal Eldin

Tanta University, Egypt

Mohamed Mansour, UK

Sabbah Hammoury

Alexandria Ayadi Almostaqbal

Oncology Hospital, Egypt

Nehal Aboulfotoh

Zewail City for Science and

Technology, Cairo, Egypt

Amir Elkhami

Galaxo, San Francisco, USA

Rabab Khairat

National Research Center,

Giza, Egypt

Ahmed Alzohairy

Zagazi University, Egypt

Wgady Khalil

National Research Center, Egypt

Sayed Bakry

Alazhar University, Egypt

Mohamed Ghanem, MD

Kafr Elshikh University, Egypt

Mohamed Salama, MD

Mansoura University, Egypt

Mona Marie, MD

Alexandria University, Egypt

\section{For more information, contact}

Hamdi Kandil

Tanta University, Egypt

Email: ljcbr100@gmail.com 